\title{
DAKWAH KULTURAL MUHAMMADIYAH TERHADAP KAUM AWAM
}

\author{
Amrullah Husein \\ amrullahhusein1988@gmail.com
}

\begin{abstract}
Muhammadiyah as an Islamic movement based on the Qur'an and Sunnah with tajdid movement inherent in him always carrying the mission of amar ma'ruf nahi mungkar in all areas of life. In order to make Islam a rahmatan li al-'alamin then Muhammadiyah adopt various approaches and strategy of da'wah, among others through Cultural Da'wah. Cultural da'wah as an approach and strategy of da'wah in the context of actualization of Islamic teachings in the midst of the dynamics of culture and social change in a society run gradually in accordance with the conditions of local communities. The focus of cultural da'wah lies in awareness of faith so that people are willing to accept and fulfill all Islamic teachings covering aqidah, worship, morality, and muamalah by considering the stages of social change based on social, economic, cultural, and political plurality of a society so that finally the ideal stage Islamic society can be achieved as the main mission of the Islamic message.

Muhammadiyah's concept of cultural propagation essentially relies on two aspects, aspects of dynamism and purification. First, the dynamics appreciate the potential and the tendency of human beings as cultural beings, to make efforts so that culture can bring to the progress and enlightenment of human life. Secondly, purification tries to avoid the preservation of culture that is evident in terms of Islamic teachings are shirk, superstition, bid'ah and khurafat.
\end{abstract}

Keywords: Dakwah, Muhammadiyah and Kultural 


\section{A. PENDAHULUAN}

Dakwah amar ma'ruf nahi mungkar merupakan kewajiban bagi setiap individu muslim. Islam tidak akan seperti sekarang ini tanpa adanya peran para da'i yang menyebarkan ajaran Islam. Melalui proses yang panjang dakwah Islam dapat tersebar di Indonesia dan mendapat respon yang sangat baik oleh banyak kalangan masyarakat di Indonesia. Dakwah ini juga tidak terlepas dari peran organisasi-organisasi Islam yang ada di Indonesia. Misalnya Nahdhatul Ulama (NU), Muhammadiyah, Persis, dan lain-lain.

Muhammadiyah sebagai gerakan Islam yang berlandaskan al-Qur'an dan Sunnah dengan gerakan tajdid yang melekat dalam dirinya senantiasa melaksanakan dakwah amar ma'ruf nahi mungkar di segala bidang kehidupan. Gerakan ini dilakukan melalui dakwah Islam dengan menggunakan pemikiran-pemikiran dan langkah-langkah untuk mewujudkan amalan-amalan Islam di kehidupan pribadi, keluarga, masyarakat, dan negara. Dakwah Islam yang dilakukan Muhammadiyah pada hakekatnya merupakan kelanjutan dari risalah yang telah dibawa oleh Rasulullah Muhammad SAW kepada umat manusia. Dengan misi utama menjadikan Islam sebagai rahmatan li al-'alamin.

"Dan Tiadalah Kami mengutus kamu, melainkan untuk (menjadi) rahmat bagi semesta alam."1

Islam sebagai rahmatan li al-alamin mengandung pesan tentang kehidupan universal bagi semua umat manusia baik muslim maupun non-muslim, masyarakat priyayi maupun awam, kalangan santri maupun abangan.

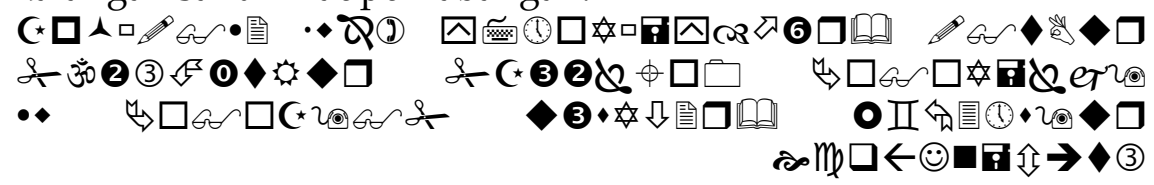

“Dan Kami tidak mengutus kamu, melainkan kepada umat manusia seluruhnya sebagai pembawa berita gembira dan sebagai

${ }^{1}$ Departemen Agama RI, Al-Qur'an dan Terjemah, Bandung: Syamil Cipta Media, h. 331. 


\section{1 beri peringatan, tetapi kebanyakan manusia tiada mengetahui." 2}

Islam menganjurkan kearifan dalam memahami realitas masyarakat yang sifatnya ma'ruf dan mencegah kemunkaran dengan memperhatikan keadaan dan kecenderungan manusia beserta sifat dan karakternya. Dakwah Islam dilakukan sebijaksana mungkin dengan memperhatikan situasi dan kondisi objek dakwah, baik kemampuan intelektual masyarakat maupun kondisi psikologi perkembangannya. Demikian halnya ketika menghadapi masyarakat awam yang relatif memiliki kemampuan intelektual yang rendah. Tetapi terkadang masyarakat awam memiliki kemampuan spiritual yang tinggi.

Dalam rangka menjadikan Islam sebagai rahmatan li al-'alamin maka Muhammadiyah menempuh berbagai pendekatan dan strategi dakwah, antara lain melalui Dakwah Kultural. Dakwah kultural sebagai suatu pendekatan dan strategi dakwah dalam konteks aktualisasi ajaran Islam di tengah dinamika kebudayaan dan perubahan sosial dalam suatu masyarakat dijalankan secara bertahap sesuai dengan kondisi masyarakat setempat. Fokus dakwah kultural terletak pada penyadaran iman sehingga umat bersedia bersedia menerima dan memenuhi seluruh ajaran Islam meliputi aqidah, ibadah, akhlak, dan muamala 113 igan memperhatikan tahapan perubahan sosial berdasarka . litas (keanekaragaman) sosial, ekonomi, budaya, dan politik suatu masyarakat sehingga akhirnya tahapan ideal masyarakat Islami dapat tercapai sebagaiman misi utama risalah Islam.

Dalam menghadapi berbagai kemajemukan masyarakat dan situasi yang semakin kompleks, Muhammadiyah perlu melakukan pendekatan dan strategi khusus terutama dalam menghadapi maasyarakat awam yang mayoritas masih relatif sangat rendah pemahamannya tentang ajaran Islam dan sangat lekat dengan kebudayaan dan tradisi. Salah satu strategi dakwah Muhammadiyah yang dianggap sangat perlu dalam menghadapi masyarakat awam yaitu Dakwah Kultural. Dakwah Kultural yang dimaksud Muhammadiyah ialah upaya menanamkan nilai-nilai Islam dalam seluruh dimensi kehidupan dengan memperhatikan potensi dan kecenderungan manusia sebagai makhluk budaya secara luas dalam rangka mewujudkan masyarakat Islam yang

\footnotetext{
${ }^{2}$ Ibid, h. 431.
} 
sebenar-benarnya. Dengan demikian sebenarnya konsep dakwah kultural bagi Muhammadiyah bukanlah sesuatu yang $k$ bahkan gerakan Muhammadiyah yang dirintis Kyai Haji Ah Dahlan sejak berdirinya bercorak kultural, dapat diterima oleh semua kalangan termasuk masyarakat awam. Sehingga dakwah Muhammadiyah mampu mengembangkan Amal Usaha Muhammadiyah seperti sekarang ini.

Berdasarkan latar belakang masalah tersebut di atas, maka Muhammadiyah perlu melakukan pendekatan dakwah kultural. Hal inilah yang membuat penulis tertarik untuk menulis skripsi dengan judul: Konsep Dakwah Kultural Muhammadiyah Terhadap Masyarakat Awam.

\section{B. PENGERTIAN DAKWAH}

Secara etimologi dakwah adalah berasal dari kata" $d a^{\prime} a$, yad'u, da'watan " yang bermakna memanggil, mengundang, dan mengajak ${ }^{3}$.

Menurut Yusuf Al-Qardhawi :

"Dakwah di jalan Allah SWT adalah mengajak manusia kepada agama Allah, mengikuti petunjuk-Nya, memberlakukan aturan Nya di atas bumi, serta mentauhidkan Allah swt dalam ibadah, minta pertolongan dan ketaatan. Berlepas diri dari semua taghut yang ditaati selain Allah, membenarkan apa yang dinyatakan benar oleh Allah dan menyalahkan apa yang dinyatakan salah, menyuruh pada kebaikan, mencegah kemungkaran dan berjihad di jalan Allah." 4

Secara terminologis, menurut Prof. Toha Yahya Omar, dakwah adalah mengajak manusia dengan cara bijaksana kepada jalan yang benar sesuai dengan perintah Tuhan untuk keselamatan dan kebahagiaan mereka di dunia dan di akhirat. ${ }^{5}$

${ }^{3}$ A.W. Munawir, Kamus Al Munawir Arab Indonesia Terlengkap, Surabaya : Penerbit Pustaka Progresip 1997, h. 406.

4 Musthaffa Malaikah, Manhaj Dakwah Yusuf Al- Qaradhawi Harmoni Antara Kelembutan dan Ketegasan, Jakarta : Pustaka Al-Kautsar 2001, Cet. Ke-1.h. 1.

${ }^{5}$ Toha Yahya Omar, Ilmu Dakwah, Jakarta: Wijaya, 1985, h. 1. 
Menurut Amrullah Ahmad bahwa pada hakikatnya, dakwah Islam merupakan aktualisasi iman (teologis) yang 93 ifestasikan dalam suatu sistem kegiatan manusia beriman I bidang kemasyarakatan yang dilaksanakan secara teratur untuk mempengaruhi cara merasa, berfikir, bersikap, dan bertindak manusia pada dataran kenyataan individual dan sosiokultural dalam rangka mengusahakan terwujudnya ajaran Islam dalam semua segi kehidupan dengan menggunakan cara tertentu. ${ }^{6}$

Pengertin tersebut menjelaskan bahwa aktivitas dakwah merupakan kegiatan yang dilaksanakan secara sadar dalam upaya mengembangkan agama Allah agar objek dakwah (mad'u) melaksanakan ajaran agama dengan baik. Lebih jelasnya, agar manusia bisa mencapai kebahagiaan baik di dunia maupun di akhirat.

Sebagaimana dinyatakan oleh Syaikh Ali Mahfudz seorang ulama dari Mesir, yang dimaksud dengan dakwah adalah mengajak manusia atas kebaikan dan petunjuk, dan beramar ma'ruf dan nahi mungkar, untuk memperoleh kebahagiaan di dunia dan akhirat. ${ }^{7}$

Oleh karena itu, cakupan dakwah adalah sangat luas karena dakwah dilaksanakan mencakup perbaikan berbagai dimensi kehidupan manusia, baik pendidikan, ekonomi, sosial, politik, maupun dimensi lain.

Dalam realitas sekarang ini, pengertian tentang dakwah, disalahpahami oleh masyarakat dewasa ini. Dakwah biasanya dikesankan sebagai ceramah, pidato, khutbah, dan sejenisnya. Sehingga kesan yang muncul adalah bahwa dakwah merupakan kepandaian praktis dalam berpidato. Tentulah hal ini adalah sangat keliru. Ceramah atau berpidato dan pengertian sejenis adalah bagian dari dakwah atau salah satu dari metode dakwah.

Oleh karena itu, missunderstanding mengenai dakwah tersebut, harus dikembalikan pada jalur yang sebenarnya. Menurut Sayyid

${ }^{6}$ Amrullah Ahmad, Dakwah Islam dan Perubahan Sosial, Yogyakarta: PLP2M, 1983, h. 3.

7 Ali Makhfudz, Hidayat al-Mursyidin, Kairo: Dar al-Kutub alArabiyyah, 1954, h. 17. 
Muhammad Alwi, dakwah dapat dikelompokkan dala tiga kategori, yaitu:

a. Dakwah bi al-lisan

Dakwah bi al-lisan adalah dakwah yang dilaksanc ${ }^{1 \ldots . . .}$ melalui lisan, yang dilakukan antara lain dengan cerar 94 pidato, diskusi, nasihat, dan lain-lain.

b. Dakwah bi al-hal

Dakwah bi al-hal adalah dakwah dengan perbuatan nyata yang meliputi keteladanan. Misalnya dengan tndakan amal nyata yang dari karya nyata tersebut hasilnya bisa dirasakan secara kongkrit oleh masyarakat, seperti pembangunan rumah sakit, panti asuhan, sekolah-sekolah, pondok pesantren, panti jompo, dan lain-lain.

c. Dakwah bi al-qalam

Dakwah bi al-qalam adalah dakwah melalui tulisan yang dilakukan dengan keahlian menulis di media massa seperti surat kabar, majalah, buku, maupun internet. ${ }^{8}$

Dengan memahami secara cermat pembagian dakwah tersebut, maka jelaslah bahwa dakwah tidak cukup diidentikkan dengan ceramah atau pidato belaka. Ceramah atau pidato hanyalah sebagian dari salah satu metode dakwah. Pengertian dakwah sangatlah luas, dalam hal ini di samping dakwah yang dilakukan dengan lisan, misalnya melalui media penyiaran (broadcasting) kepandaian dakwah bi al-qalam (journalism) juga perlu digalakkan sebagai perwujudan dakwah di era globalisasi. Demikian pula dakwah bi al-hal yang menyangkut kepentingan masyarakat banyak.

Dakwah adalah tugas para Rasul dan para nabi yang merupakan hamba Allah pilihan, dan duta-duta untuk makhlukNya. Ia juga tugas para pewaris rasul yang terdiri dari kalangan ulama yang amilin, para rabbaniyin yang shadiqin. Dakwah adalah amal paling baik setelah iman kepada Allah. Karena buah dakwah adalah menjadikan manusia mendapat hidayah serta kecintaan mereka terhadap kebaikan, menjauhkan mereka dari kebatilan dan mengeluarkan mereka dari kegelapan cahaya. Allah berfirman:

${ }^{8}$ Sayyid Muhammad Alwi, Kiat Sukses Berdakwah, Jakarta: Amzah, 2006, h. 18. 


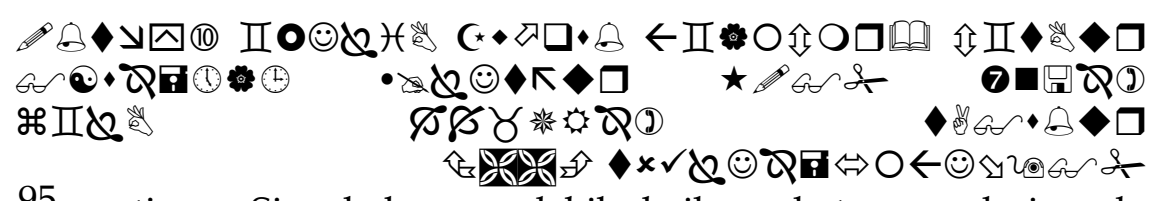

95 rtinya: Siapakah yang lebih baik perkataanya dari pada orang yang menyeru kepada Allah, mengerjakan amal sholih dan berkata," Sesungguhnya aku termasuk orang-orang yang menyerahkan diri," (Surat Fushilat ayat 33) ${ }^{9}$

\section{PENGERTIAN DAKWAH KULTURAL}

Dakwah kultural adalah dakwah yang dilakukan dengan cara mengikuti budaya-budaya kultur masyarakat setempat dengan tujuan agar dakwahnya dapat diterima di lingkungan masyarakat setempat. 10

Dakwah kultural juga bisa berarti kegiatan dakwah dengan memperhatikan potensi dan kecenderungan manusia sebagai makhluk budaya secara luas dalam rangka menghasilkan kultur baru yang bernuansa Islami atau kegiatan dakwah dengan memanfaatkan adat, tradisi, seni dan budaya lokal dalam proses menuju kehidupan Islami. ${ }^{11}$

Jadi dakwah kultural merupakan upaya menanamkan nilainilai Islam dalam seluruh dimensi kehidupan dengan memperhatikan potensi dan kecenderungan manusia sebagai makhluk budaya secara luas, dalam rangka mewujudkan masyarakat Islam yang sebenar-benarnya.

Dakwah kultural mencoba mamahami potensi dan kecenderungan manusia sebagai makhluk budaya yang berarti memahami ide-ide, adat istiadat, kebiasaan, nilai-nilai, norma, sistem aktivitas, simbol, dan hal-hal fisik yang memiliki makna tertentu dan hidup subur dalam kehidupan masyarakat. Pemahaman tersebut dibingkai oleh pandangan dan sistem nilai ajaran Islam yang membawa pesan rahmatan li al-alamin.

${ }_{9}$ Departemen Agama RI, Al-Qur'an dan Terjemah, Bandung: Syamil Cipta Media, h. 17.

${ }^{10}$ Muhammad Arifin, "Dakwah Kultural" dalam http://alumnifiad.youneed.us/dakwah-kultural-f14/dakwah-kultural-t43.htm, (download: 14.30 wib, 22 Januari 2010).

11 Ibid. 
Dengan demikian dakwah kultural menekankan pada dinamisasi dakwah, selain pada purifikasi. Dinamisasi berarti mencoba untuk mengapresiasi (menghargai) potensi dan kecenderungan manusia sebagai makhluk budaya dalam arti 1...sekaligus melakukan usaha-usaha agar budaya tersebut memk 96 kepada kemajuan dan pencerahan hidup manusia. Sedangkan purifikasi mencoba untuk menghindari pelestarian budaya yang nyata-nyata dari segi ajaran Islam bersifat syirik, takhayul, bid'ah dan khurafat. Karena itu, dakwah kultural bukan berarti melestarikan atau membenarkan hal-hal yang bersifat syirik, bid'ah, tahayul dan khurafat, tetapi cara memahami dan menyikapinya dengan menggunakan kacamata atau pendekatan dakwah. ${ }^{2}$

\section{MUHAMMADIYAH}

\section{Menurut Bahasa}

Muhammadiyah berasal dari bahasa Arab 'Muhammad', yaitu nama Nabi dan Rasul Allah yang terakhir, kemudian mendapat tambahan 'ya' nisbah, yang artinya menjeniskan atau menisbahkan. Jadi yang dimaksud dengan Muhammadiyah yaitu 'umat Muhammad Shallallahu'alaihi wasallam' atau 'pengikut Muhammad Shallallahu'alaihi wasallam' yaitu semua orang Islam yang mengakui dan meyakini bahwa Nabi Muhammad Shallallahu'alaihi wasallam adalah hamba dan pesuruh Allah yang terakhir. ${ }^{13}$

\section{Arti Istilah (Terminologi)}

Muhammadiyah adalah gerakan Islam, dakwah amar ma'ruf nahi munkar, berakidah Islam dan bersumber pada Qur'an dan Sunnah yang didirikan oleh Kyai Haji Ahmad Dahlan pada tanggal 8 Dzulhijjah 1330 Hijriyah bertepatan dengan tanggal 18 November 1912 Miladiyah di Kota Yogyakarta. Gerakan ini diberi nama Muhammadiyah oleh pendirinya dengan maksud untuk bertafaul (berpengharapan

12 Pimpinan Pusat Muhammadiyah, Dakwah Kultural Muhammadiyah, Yogyakarta: Suara Muahammadiyah, 2004, Cet ke-1, h. 26

${ }^{13}$ Musthafa Kamal Pasha, et.al, Muhammadiyah Sebagai Gerakan Tajdid, Yogyakarta: Citra Karsa Mandiri, 2000, h. 43. 
baik) dapat mencontoh jejak perjuangan Nabi Muhammad Shallallahu'alaihi wasallam dalam rangka menegakkan dan menjunjung tinggi agama Islam semata-mata demi terwujudnya izzu al-Islam wa al-Muslimin, kejayaan Islam sebagai cita-cita/idealita dan kemuliaan hidup ummat Islam sebagai realita. ${ }^{14}$

\section{E. MAKSUD DAN TUJUAN MUHAMMADIYAH}

Kyai Haji Ahmad Dahlan memprakarsai berdirinya Muhammadiyah tentunya mempunyai maksud dan tujuan tertentu. Sebagaimana keinginan KHA. Dahlan, Muhammadiyah haruslah selalu tumbuh dan berkembang sehingga dapat member manfaat yang sebesar-besarnya sepanjang masa kepada umat Islam khususnya dan masyarakat luas pada umumnya, maka maksud dan tujuan Muhammadiyah telah pernah mengalami beberapa kali perubahan sesuai dengan situasi dan kondisi umat dan masyarakat.

Adapun rumusan maksud dan tujuan Muhammadiyah terakhir yang telah diputuskan ialah "Menegakkan dan Menjunjung Tinggi Agama Islam Sehingga Terwujud Masyarakat Islam yang Sebenarbenarnya". ${ }^{15}$

Pengertian yang terkandung dalam rumusan maksud dan tujuan Muhammadiyah dapat dijelaskan sebagai berikut :

a. Menegakkan dan menjunjung tinggi Agama Islam. Menegakkan maksudnya ialah berusaha menyucikan dan memurnikan pemahaman Agama Islam dengan sebenarbenarnya dan sesungguh-sungguhnya sesuai dengan maksud al-Qur'an dan al-Sunnah, serta berusaha memberikan pelajaran tentang ajaran Agama Islam kepada masyarakat, kemudian menggerakkan dan membimbing pengamalan ajaran Agama Islam secara tepat dan mantap. Sedangkan menjunjung tinggi maksudnya, bagi dan dalam Muhammadiyah, ajaran Agama Islam harus diletakkan di atas segala-galanya. Muhammadiyah berpendirian, Agama Islam itu risalah (pesan pengarahan) Allah kepada manusia, menjadi satu-satunya petunjuk dan pedoman hidup dan kehidupan, yang lengkap dan sempurna,

14 Ibid, h. 44.

15 Ibid, h. 29 
sebagai rahmat li al-alamin, dan memiliki kebenaran mutlak. Hanya Agama Islamlah satu-satunya yang d dijadikan senddi untuk mengatur ketertiban hi 98 bersama sepanjang masa. ${ }^{16}$

b. Masyarakat Islam yang sebenar-benarnya adalah masyarakat Islam yang menjalankan syari'at Islam sesuai dengan yang diajarkan oleh Rasulullah Shallallahu 'alaihi wasallam berlandaskan al-Qur'an dan al-Sunnah alShahihah.

Agama Islam yang berupa risalah Allah yang sumbernya adalah wahyu, telah mengajarkan kepada seluruh umat Islam agar:

a. Selalu bersikap hormat, mengindahkan dan mengamalkan ajaran-ajaran Islam yang terkandung di dalam al-Qur'an dan al-Sunnah dengan sebenar-benarnya dan sesungguhsungguhnya.

b. Selalu menjaga Agama Islam agar tetap dalam kemurniannya sesuai dengan yang dikehendaki oleh Allah dan Rasul-Nya, tidak ternoda oleh ajaran yang sesat dan menyesatkan, dan selamat dari tipu daya musuh-musuh Islam yang senantiasa berusaha untuk menghncurkannya. ${ }^{17}$

\section{F. KONSEP DAKWAH KULTURAL MUHAMMADIYAH TERHADAP MASYARAKAT AWAM}

Dakwah Kultural adalah sebuah pengistilahan bagaimana Muhammadiyah dalam berdakwah melalui wahana adat, tradisi, dan budaya lokal. Muhammadiyah menganggap bahwa tidak benar budaya lokal tidak dapat diperankan sebagai wahana dakwah. Penolakan terhadap budaya lokal selama ini mengakibatkan Muhammadiyah didominasi oleh aspek aqidah dan fiqhiyah dalam pengertian yang sempit. Sehingga kesan yang ditangkap pada masyarakat, dakwah Muhammadiyah terlalu keras dan suka membid'ahkan. Bahkan muncul bahasa seolaholah Muhammadiyah membawa ajaran baru.

16 Ibid, h. 30.

17 Ibid. 
Salah satu keputusan Tanwir Muhammadiyah di Makassar tahun 2003 lalu adalah menggagas model dakwah kultural Muhammadiyah sebagai strategi perluasan dakwah .. Immadiyah. Kalau selama ini dakwah Muhammadiyah lebih 99 ssentrasi pada kalangan abangan dan kaum perkotaan semata, maka dengan perubahan dan gerak zaman yang begitu cepat, perlu adanya rumusan yang jelas menyangkut segmen pedesaan untuk menjadi sasaran dakwah Muhammadiyah ke depan. ${ }^{18}$

Dakwah kultural adalah bagian dari strategi tersebut yang ingin dilaksanakan oleh Muhammadiyah. Selain itu, dakwah kultural merupakan bentuk lain pemekaran metode dakwah dalam tubuh Muhammadiyah yang selama ini hanya pada metode purifikasi/pemurnian. Sehingga cara yang selama ini setidaknya dapat membuka model dakwah Muhammadiyah yang lebih bersifat akomodatif, dinamis, dan kreatif. Sebab selama ini tidak jarang terjadi, ketika sejumlah kader Muhammadiyah menuturkan cerita tatkala terjun langsung dalam masyarakat awam, ternyata banyak asumsi dakwah Muhammadiyah. Sedikit-sedikit Muhammadiyah mengatakan "haram", "syirik", "bid'ah", "khurafat", dan lain sebagainya, yang ujung-ujungnya melarang keras sesuatu yang masih berkaitan dengan tradisi setempat.

Oleh karena itu, dakwah Muhammadiyah terkesan sangat garang memberangus keberadaan pribumi. Selain itu, dakwah Muhammadiyah juga terkesan elitis karena hanya untuk kalangan tertentu saja konsep pemahaman keislamannya bisa diterima. Hanya bagi mereka yang tingkat rasionalitasnya lebih tinggi dan pernah mengenyam pendidikan tinggi yang bisa memahami konsep pemahaman Islam model Muhammadiyah.

Maka, Imam Muchlas menganggap pentingya dakwah kultural bagi Muhammadiyah, hal ini dimaksudkan agar dakwah Muhammadiyah tidak hanya dipahami dan diterima oleh kalangan perkotaan dan kalangan elit semata. Karena banyak sekali dinamika kultur lokal dan variasi-variasinya yang jauh dari perhatian dan jangkauan elit Muhammadiyah. Dakwah kultural dapat dijadikan salah satu kacamata baru dalam melihat

${ }^{18}$ Imam Muchlas, Landasan Dakwah Kultural, Yogyakarta: Surya Sarana Utama, 2006, h. 6 
multiaspek dari keberagaman tradisi lokal agar dakwah dapat dijadikan salah satu media transformasi sosial. ${ }^{19}$

Aktivitas dakwah kultural di Muhammadiyah itu sendiri meliputi seluruh aspek kehidupan, baik yang menyangkut ; sosial budaya, pendidikan, ekonomi, kesehatan alam, 100 sebagainya. Keberhasilan dakwah kultural ini ditandai dengan teraktualisasikan dan terfungsinya nilai-nilai Islan dalam kehidupan pribadi, rumah tangga, kelompok masyarakat, dan cakupan kehidupan lainnya.

\section{Dakwah Kultural Melalui Pendekatan Budaya Lokal}

Membahas tentang dakwah kultural dalam konteks budaya lokal berarti mencari bentuk pemahaman dan aktualisasi gerakan dakwah Islam dalam realitas kebudayaan masyarakat Indonesia, khususnya di kalangan umat Islam, melalui pendekatan dan strategi yang tepat.

Kebudayaan merupakan suatu hal yang sangat lekat dengan masyarakat, sehingga dalam beragama pun masyarakat masih sangat terikat dengan budaya. Keadaan ini paling banyak dialami oleh masyarakat yang cenderung memiliki pengetahuan dan pemahaman Islam yang rendah.

Dalam konteks ini upaya untuk memahami aktivitas masyarakat yang sering dikategorikan sebagai kegiatan keagamaan yang bercorak budaya dapat dibedakan antara yang berdimensi ritual keagamaan dengan yang berdimensi semata-mata budaya, sehingga tidak melahirkan pendekatan dan cara dakwah yang serba konfrontasi agar tidak kehilangan nilai kearifan (hikmah), persuasi (mau'idhah hasanah), dan nilai dialogis (mujadalah billati hiya ahsan).

\section{Dakwah Kultural Melalui Apresiasi Seni}

Selain dengan menggunakan pendekatan budaya lokal, Muhammadiyah perlu menerapkan kesenian sebagai metode dakwahnya terhadap masyarakat awam. Karena masyarakat lebih tertarik apabila dakwah itu dikemas sedemikian rupa dengan nilai-nilai estetika, sehingga tidak monoton dengan metode ceramah yang membosankan. Dengan dakwah melalui kesenian dapat memikat hati objek terlebih dahulu, sehingga kemudian ia bisa mengikuti dakwah Muhammadiyah selanjutnya. 
Islam adalah agama yang sesuai dengan fitrah manusia. Jika beragama Islam merupakan fitrah manusia, maka berkesenian pun adalah naluri manusia. Berpijak pada nilai101

:1-i fitrah kemanusiaan yang cenderung kepada kebenaran 1 L kebajikan, maka sesungguhnya berkesenian yang mengekspresikan keindahan itu juga dapat merefleksikan nilainilai kebenaran dan kebajikan bagi kemaslahatan hidup umat manusia. ${ }^{20}$

\section{Dakwah Kultural Melalui Multimedia}

Selain dengan pendekatan kultur lokal dan kesenian, dakwah kultural Muhammadiyah terhadap masyarakat awam juga harus didukung dengan teknologi informasi dan komunikasi. Yang mana pada saat ini media informasi telah menjadi media yang sangat stategis untuk dijadikan media dakwah. Karena media informasi dan komunikasi seperti surat kabar, radio, dan televisi tidak hanya dikonsumsi oleh masyarakat yang tinggal di perkotaan dan masyarakat marjinal saja, tetapi sudah merambah ke daerah-daerah pelosok yang nobane mereka sangat awam terhadap ilmu agama.

Pengaruh media informasi ini dapat kita rasakan saat ini. Perilaku-perilaku menyimpang yang dilakukan oleh beberapa oknum tidak lain merupakan dampak negatif dari media informasi yang menampilkan nilai-nilai yang sangat jauh dari nilai-nilai yang islami.

Menyikapi hal ini, maka Muhammadiyah perlu melakukan strategi dakwah terhadap masyarakat awam yang cenderung menangkap seluruh informasi melalui media tersebut. Salah satunya yaitu dengan memanfaatkan media tersebut sebagai sarana dakwah amar ma'ruf dan nahi mungkar. Dengan ini diharapkan dakwah melalui media dapat mengurangi dampak negatif yang diakibatkan oleh pengaruh informasi yang jauh dari nilai-nilai islami.

\section{G. KESIMPULAN}

${ }^{20}$ Ibid, h. 53 
Setelah dibahas beberapa konsep dakwah kultural Muhammadiyah terhadap masyarakat awam, maka bisa disimpulkan bahwa :

1. Konsep dakwah kultural Muhammadiyah pada hakikatnya bertumpu pada dua aspek, aspek dinamisasi dan purifikasi. Pertama, dinamisasi menghargai potens $\mathrm{d}$ (nn kecenderungan manusia sebagai makhluk bu 102 melakukan usaha-usaha agar budaya tersebut aapat membawa kepada kemajuan dan pencerahan hidup manusia. Kedua, purifikasi mencoba untuk menghindari pelestarian budaya yang nyata-nyata dari segi ajaran Islam bersifat syirik, takhayul, bid'ah dan khurafat.

2. Dakwah kultural Muhammadiyah dalam penerapan masyarakat awam dilakukan dengan tiga cara, pertama melalui pendekatan budaya lokal, kedua melalui pendekatan kesenian, dan ketiga melalui pendekatan multimedia (media cetak dan media elektronik).

\section{DAFTAR PUSTAKA}

Ahmad Amrullah, Dakwah Islam dan Perubahan Sosial, Yogyakarta: PLP2M, 1983.

Departemen Agama RI, Al-Qur'an dan Terjemah, Bandung: Syamil Cipta Media

Kamal Pasha Musthafa, et.al, Muhammadiyah Sebagai Gerakan Tajdid, Yogyakarta: Citra Karsa Mandiri, 2000.

Makhfudz Ali, Hidayat al-Mursyidin, Kairo: Dar al-Kutub alArabiyyah, 1954.

Malaikah Musthaffa, Manhaj Dakwah Yusuf Al- Qaradhawi Harmoni Antara Kelembutan dan Ketegasan, Jakarta : Pustaka AlKautsar 2001.

Muchlas Imam, Landasan Dakwah Kultural, Yogyakarta: Surya Sarana Utama, 2006. 
Muhammad Alwi Sayyid, Kiat Sukses Berdakwah, Jakarta: Amzah, 2006.

Muhammad Arifin, "Dakwah Kultural" dalam $103 \frac{\text { http://alumnifiad.youneed.us/dakwah-kultural-f14/dakwah- }}{\text { kultural-t43.htm, (download: } 14.30 \text { wib, } 22 \text { Januari 2010). }}$

Munawir A.W., Kamus Al Munawir Arab Indonesia Terlengkap, Surabaya : Penerbit Pustaka Progresip 1997.

Pimpinan Pusat Muhammadiyah, Dakwah Kultural Muhammadiyah, Yogyakarta: Suara Muahammadiyah, 2004.

Yahya Omar Toha, Ilmu Dakwah, Jakarta: Wijaya, 1985. 